\title{
Fatigue Life Estimation of Welds on Truck Frames for Rolling Stock Based on Stress Frequency Caused by Service Loads*
}

\author{
Yasutomo ODA**, Tsuyoshi YAGI**, \\ Tomohiro OKINO** and Hiromichi ISHIDUKA** \\ **Department of Vehicle Structure Technology, Railway Technical Research Institute \\ 2-8-38 Hikari-cho, Kokubunji-Shi, Tokyo, 185-8540, Japan
}

\begin{abstract}
The fatigue strength of weld surfaces on truck frames has been estimated according to the fatigue limit diagram in JIS E 4207, General Rules for Design of Truck Frames for Railway Rolling Stock. However, it is not possible to predict actual fatigue life using this diagram. This study demonstrates the possibility of fatigue life estimation for welds on truck frames based on a modified Miner's rule. In order to estimate fatigue life, three factors are needed: the S-N diagram assumed from the allowable stress in JIS E 4207 or the JSSC fatigue design curve, the relationship between crack occurrence and running distance, and the stress frequency distribution caused by service loads.
\end{abstract}

Keywords: Railway, Truck Frame, Welding, Stress Frequency, Fatigue, Life Prediction

\section{Introduction}

The fatigue strength of weld surfaces on truck frames has been estimated according to the fatigue limit diagram in JIS E 4207-2004 ${ }^{(1)}$, General Rules for Design of Truck Frames for Railway Rolling Stock (referred to below as JIS) using the maximum stress estimated by the design load at the design stage (referred to below as the design stress) or obtained by measurement in a running test. The fatigue limit diagram takes the toe of a weld as the target for strength estimation. The toe is finished with a radius of $3 \mathrm{~mm}$, and the stress is measured with a strain gauge of $5 \mathrm{~mm}$ in length attached to it.

As most truck frames are annealed, a fatigue limit diagram that considers mean stress is used. The fatigue allowable stress of unfinished welds for which the mean stress is 0 is 70 $\mathrm{MPa}$, regardless of the shape of the weld joint. This is considered to be a strength of $2 \times$ $10^{6}$ with a destruction probability of $0.1 \%{ }^{(2)}$.

The stress caused by service loads as measured in the running test shows that the one-way running distance for measurement is about $100 \mathrm{~km}$ in most instances. Examples of damage in the past agree well with the estimation results obtained using this diagram ${ }^{(3)}$. However, as estimation using the fatigue diagram is limited only to the examination of whether the maximum stress exceeds the fatigue allowable stress, it is not possible to predict fatigue life based on the stress frequency caused by service loads.

In most standards of fatigue design for steel structures ${ }^{(5)-(8)}$ such as the Japanese Society of Steel Construction (JSSC) recommendation for fatigue design ${ }^{(4)}$, fatigue life is estimated from the fatigue design curve and stress frequency for each weld joint. In such cases, nominal stress values are generally used. Another estimation method involves the use of the hot spot stress values in these standards ${ }^{(4)-(6)}$. Hot spot stress is defined as the

\footnotetext{
*Received 1 Dec., 2008 (No. T1-07-0325) Japanese Original : Trans. Jpn. Soc. Mech Eng., Vol.73, No.734, A(2007), pp.1171-1176 (Received 6 Apr., 2007) [DOl: 10.1299/jee.4.57]
} 
local amount of stress that causes fatigue damage, and its fatigue design curve bears no relation to the shape of the weld joint. The technique is therefore similar to the above-mentioned JIS method in this regard.

This study demonstrates the possibility of estimating the fatigue life of welds on truck frames using the stress frequency caused by service loads according to a modified Miner's rule. To estimate the fatigue life, the following items are used:

(1) The S-N diagram assumed using the allowable stress that bears no relation to the shape of the weld joint in JIS. In this diagram, the inverse slope of the S-N curve $m$ is 3 or 5.5.

(2) The JSCC fatigue design curve with a value of $m=3$, or the S-N diagram with a value of $m=5.5$, assumed from the JSCC fatigue design curve of 1974. These curves correspond to the shape of each weld joint.

(3) The relationship between crack occurrence vs. running distance and stress frequency distribution caused by service loads. The stress frequency distribution is set as the ineffective stress.

\section{Characteristics of stress frequency and equivalent stress per $10 \mathrm{~km}$}

\subsection{Stress measurement positions}

The stress measurement positions taken up in this paper are indicated below (see Figure 1), and were chosen from positions where damage had occurred in the past. Each one is a weld position without any finishing, and all the truck frames were manufactured between 1958 and 1965.
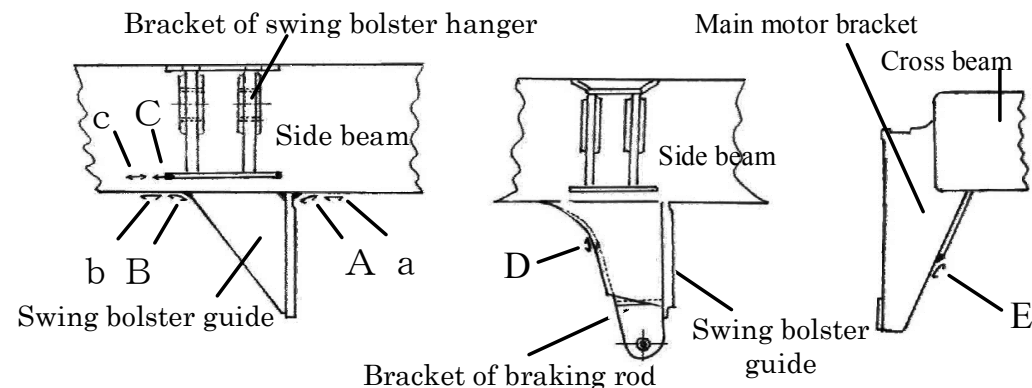

A, a, B, b, C, c

Bracket of braking rod

$\underline{\mathrm{D}}$

$\underline{E}$
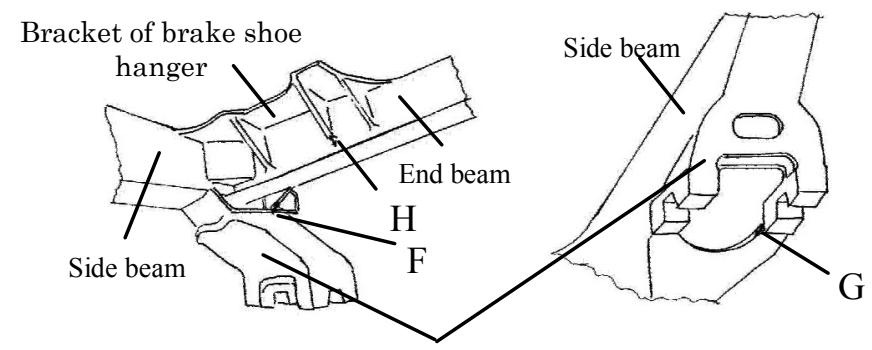

Bracket of axle box suspension

$$
\underline{\mathrm{H}, \mathrm{F}}
$$

$\underline{\mathrm{G}}$

Fig. 1 Stress measurement positions of truck frames where damage occurred in the past 
Stress measurement positions

A: toe of weld of swing bolster guide with side beam

a: solid surface of side beam near weld on swing bolster guide

B: toe of weld of swing bolster guide with side beam

b: solid surface of side beam near weld on swing bolster guide

$\mathrm{C}$ : toe of weld of swing bolster hanger bracket reinforcement with side beam

c: solid surface of side beam near weld on swing bolster hanger bracket reinforcement

D: toe of weld on braking rod bracket reinforcement

E: toe of weld on main motor bracket reinforcement

$\mathrm{F}$ : toe of weld of axle box suspension bracket reinforcement with end beam

$\mathrm{G}$ : toe of weld of axle box suspension bracket reinforcement with side beam

$\mathrm{H}$ : toe of weld of brake shoe hanger bracket reinforcement with end beam

In terms of weld joint shape classification, $\mathrm{A}(\mathrm{a})$ and $\mathrm{G}$ are one-side welding of $\mathrm{T}$ joints with a groove, $\mathrm{B}(\mathrm{b}), \mathrm{C}(\mathrm{c}), \mathrm{F}$ and $\mathrm{H}$ are one-side welding of the angle crossing $\mathrm{T}$ joints with a groove, and D and $\mathrm{E}$ are lap joints. Each joint is considered to correspond to class $\mathrm{F}$ or $\mathrm{G}$ of the JSSC fatigue design curve. The fatigue allowable stress ranges at $2 \times 10^{6}$ for classes $\mathrm{F}$ and $\mathrm{G}$ are 65 and $50 \mathrm{MPa}$ respectively, and stress is measured using a strain gauge of $5 \mathrm{~mm}$ in length. The toes of welds $\mathrm{A}-\mathrm{H}$, as the targets of strength estimation using JIS, are finished with a radius of $3 \mathrm{~mm}$, and the strain gauges are attached to them with $1 / 2-1 / 3$ of the gauge length covering the weld. On the other hand, the strain gauges were attached to the solid surface near welds $\mathrm{a}-\mathrm{c}$ as targets of strength estimation using the fatigue design curves, with the gauge center $20-30 \mathrm{~mm}$ from the toe of the weld.

\subsection{Examples of strength estimation using the JIS fatigue limit diagram}

The three apexes of the triangle on the vertical or horizontal axis shown in Fig. 2 represent the allowable stress against the yield of the material. In this case, the value is 205 $\mathrm{MPa}$, and the material is SM400. At the measurement positions of the weld toe in $\mathrm{A}-\mathrm{H}$ using the maximum stress $\sigma_{\max }$ measured in the running test, examples of fatigue strength estimated according to the JIS fatigue limit diagram are shown in the figure. All positions except $\mathrm{E}$ exceeded the fatigue limit of the weld. Damage had occurred at each of these positions in the past, indicating that this diagram is appropriate.

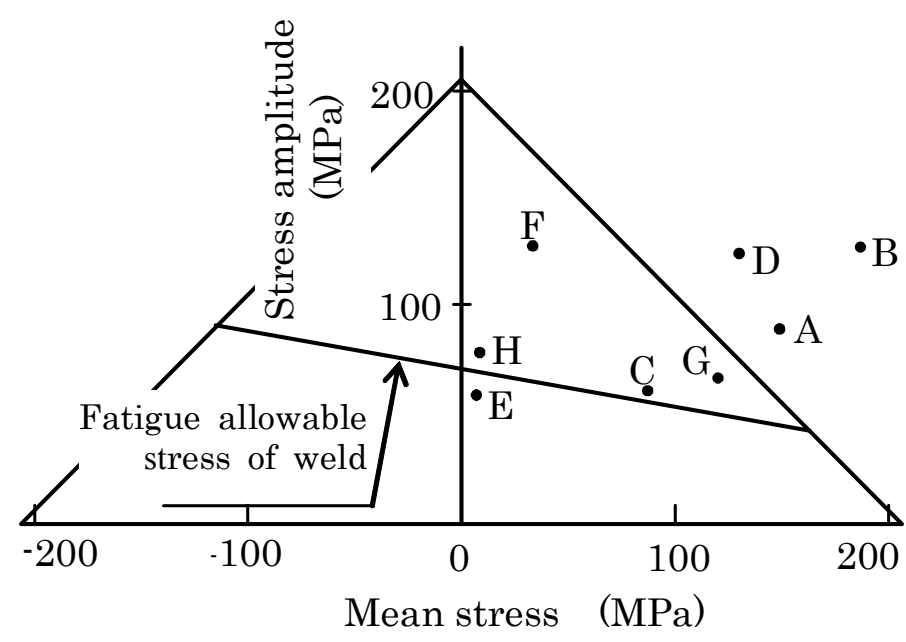

Fig. 2 Example of strength evaluation using a stress limit diagram (measurement positions $\mathrm{A}-\mathrm{H}$ ) 


\subsection{Characteristics of stress frequency distribution}

The cumulative stress frequency distributions at positions $\mathrm{A}-\mathrm{H}$ prepared according to the rain flow method using stress measured in the running test are shown in Fig. 3. In the figure, the ratio of $\sigma_{i} / \sigma_{\max }$ : stress $\sigma_{i}$ to the maximum stress $\sigma_{\max }$ is plotted on the vertical axis, and ratio $n_{i} / \Sigma n_{i}$ : frequency $n_{i}$ to total number $\Sigma n_{i}{ }^{(11)}$ is plotted on the horizontal axis.

The stress frequency distributions caused by service loads at all positions except D (where stress is generated only during braking) are distributed on the lines $\sigma_{i} / \sigma_{\max }=-$ $\log \left(n_{i} / \Sigma n_{i}\right) / \lambda$, where $\lambda=5-7$. It is therefore possible to estimate the approximate stress frequency distribution by assuming the maximum stress, e.g., the design stress value assumed at the design stage.

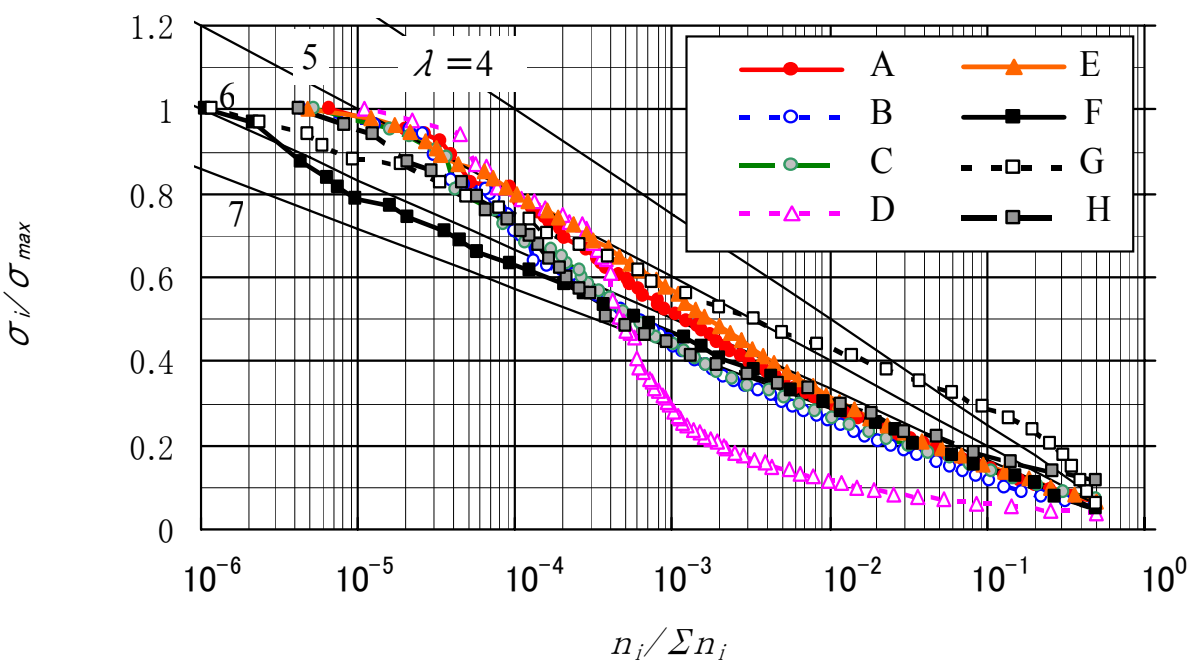

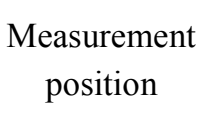

A

B

C

D

E

F

G

$\mathrm{H}$

\section{Measurement running distance \\ $(\mathrm{km})$}

480

480

480

180

180

1,060

1,060

1,060

$$
\begin{gathered}
\sigma_{i \min .} \\
(\mathrm{MPa}) \\
2.5 \\
3.75 \\
2.5 \\
2.5 \\
2.5 \\
3 \\
11 \\
10
\end{gathered}
$$

$\Sigma n_{i}$

$2.0 \times 10^{6}$

$1.9 \times 10^{6}$

$1.8 \times 10^{6}$

$2.6 \times 10^{5}$

$3.1 \times 10^{5}$

$6.8 \times 10^{5}$

$2.2 \times 10^{5}$

$1.2 \times 10^{5}$

Fig. 3 Examples of stress frequency distribution in truck welds by service load (measurement positions $\mathrm{A}-\mathrm{H}$ )

\subsection{Equivalent stress per $10 \mathrm{~km} \sigma_{e q / 10 \mathrm{~km}}$}

Generally, equivalent stress is defined as the constant amplitude that produces equivalent fatigue damage at the same accumulated frequency as that of the variable amplitude. However, in this paper, the equivalent stress per $10 \mathrm{~km} \sigma_{\text {eq } / 10 \mathrm{~km}}$ (i.e., the single amplitude that produces fatigue damage equivalent to that produced by the accumulated 
frequency of variable amplitude in a particular $10-\mathrm{km}$ section) is introduced. This value is used in evaluating fatigue life as described later, and is calculated according to a modified Miner's rule using the stress frequency distribution caused by service loads. It is calculated by the following equation:

$$
\begin{gathered}
\sigma_{e q / 10 \mathrm{~km}}=\left(\sum n_{i} \sigma_{i}{ }^{m}\right) 1 / m \\
\sigma_{e q / 10 \mathrm{~km}}: \text { Equivalent stress per } 10 \mathrm{~km} \\
\sigma_{i} \quad: \text { Stress amplitude of level } i \\
n_{i} \quad: \text { Frequency of } \sigma_{i} \text { per } 10 \mathrm{~km} \\
m \quad: \text { Inverse slope of the S-N curve }
\end{gathered}
$$

In this case, if the running distance corresponding to the fatigue life is assumed to be 1 $-2 \times 10^{7} \mathrm{~km}$, the accumulated frequency of equivalent stress per $10 \mathrm{~km} \sigma_{e q / 10 \mathrm{~km}}$ is $1-2 \times 10^{6}$.

Here, the value of $m$ is important. The JSSC fatigue design curve of 1993 uses $m=3^{(4)}$, while the former JSSC fatigue design curve published in 1974 used $m=5.5^{(9)}$. As a small stress amplitude has a large influence on fatigue life in the case of $m=3$, the estimation of fatigue life using $m=5.5$ is considered better in cases where large stress amplitudes such as maximum stress must be taken into consideration in the estimation of fatigue life for railway rolling stock.

For the case of calculating the equivalent stress per $10 \mathrm{~km} \sigma_{\text {eq/10 }} \mathrm{km}$ using the stress frequency distribution shown in Fig. 3, an example of calculations to indicate how the ineffective stress $\sigma_{c u t}$ influences the equivalent stress per $10 \mathrm{~km} \sigma_{\text {eq/10 }} \mathrm{km}$ is shown in Fig. 4. It can be seen that $\sigma_{\text {eq-cut }} / \sigma_{\text {eq } 0}$ has a tendency to decrease by increase of the ineffective stress $\sigma_{c u t} / \sigma_{\max }$ when calculated using $m=3$. However, with calculation using $m=5.5$, the ineffective stress $\sigma_{\text {cut }} / \sigma_{\max }$ has little influence on $\sigma_{\text {eq-cut }} / \sigma_{\text {eq } 0}$. In this paper, the ineffective stress $\sigma_{\text {cut }}$ is adopted such that $\sigma_{\text {cut }} / \sigma_{\text {max }}=0.2$, for which $\sigma_{\text {eq-cut }} / \sigma_{\text {eq } 0}=0.9$ with calculation using $m=3$.

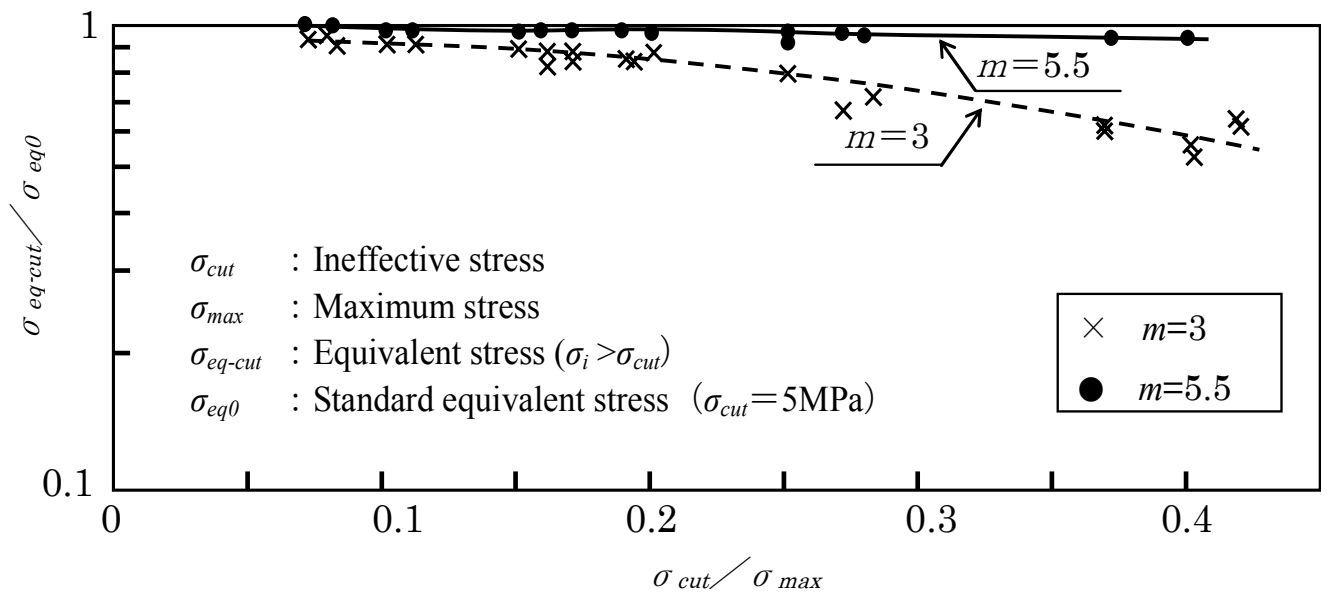

Fig. 4 Influence of ineffective stress on equivalent stress

The relationship between the maximum stress $\sigma_{\max }$ and the equivalent stress per $10 \mathrm{~km}$ $\sigma_{e q / 10 \mathrm{~km}}$ calculated by the above method is shown in Fig. 5. The maximum stress $\sigma_{\max }$ agrees well with the equivalent stress per $10 \mathrm{~km} \sigma_{e q / 10 \mathrm{~km}}$ calculated using $m=5.5$. However, $\sigma_{e q / 10 \mathrm{~km}}$ calculated using $m=3$ is significantly larger than $\sigma_{\max }$.

Here, as mentioned before, using the JIS fatigue allowable stress means that the strength corresponds to $2 \times 10^{6}$. If the running distance corresponding to the fatigue life is assumed to be $2 \times 10^{7} \mathrm{~km}$, the accumulated frequency of equivalent stress per $10 \mathrm{~km} \sigma_{\text {eq }} / 10 \mathrm{~km}$ corresponds to $2 \times 10^{6}$. In the case of calculation using $m=5.5$, the close correlation 
between $\sigma_{e q / 10 \mathrm{~km}}$ and $\sigma_{\max }$ makes it possible to replace $\sigma_{e q / 10 \mathrm{~km}}$ with $\sigma_{\max }$, and it is convenient to relate $\sigma_{\text {eq }} / 10 \mathrm{~km}$ with the estimation using $\sigma_{\max }$ of the JIS fatigue limit diagram. For example, in the execution of the fatigue test for truck frames with a running distance of $2 \times 10^{7} \mathrm{~km}, \quad \sigma_{\max }$ could be loaded with an accumulated frequency of $2 \times 10^{6}$.

In measurement positions such as $\mathrm{D}$ in the braking rod bracket, where the stress is quite small (except in positions close to that of the maximum stress $\sigma_{\max }$ ), the difference in equivalent stress per $10 \mathrm{~km} \sigma_{\text {eq }} / 10 \mathrm{~km}$ calculated using $m=3$ and that calculated using $m=5.5$ is small compared with other measurement positions. The value calculated using $m=3$ seems to be the closest to $\sigma_{\max }$ in all calculations.

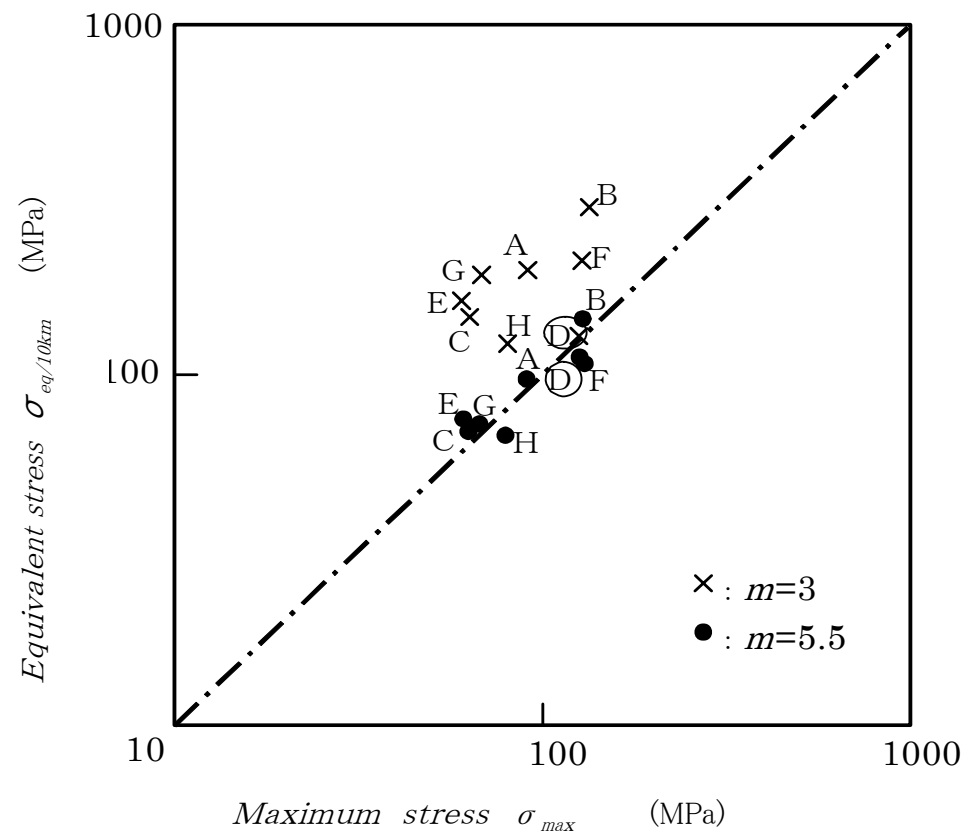

Fig. 5 Relationship between $\sigma_{e q / 10 \mathrm{~km}}$ and $\sigma_{\max }$ (measurement positions A-H)

\section{Fatigue life estimation based on past examples of damage}

\subsection{Fatigue life estimation by equivalent stress per $10 \mathrm{~km} \sigma_{\text {eq } / 10 \mathrm{~km}}$}

This chapter examines the possibility of estimating fatigue life for welds on truck frames in stress measurement positions $\mathrm{A}-\mathrm{H}$ at the toe of the weld and at $\mathrm{a}, \mathrm{b}$ and $\mathrm{c}$ on the solid surface near the weld using the equivalent stress per $10 \mathrm{~km} \sigma_{e q / 10 \mathrm{~km}}$ calculated from the accumulated stress frequency caused by service loads, and the running distance at which cracks occurred from previous examples of damage ${ }^{(13)}$.

Essentially, it is necessary to prepare an S-N diagram for each stress measurement position $\mathrm{A}-\mathrm{H}$ with consideration of the individual mean stress. However, only one $\mathrm{S}-\mathrm{N}$ diagram with stress ratio $R=0.5$ was assumed; this was prepared based on the allowable stress of $47 \mathrm{MPa}$ at $R=0.5$ obtained from the JIS fatigue limit diagram (strength at $2 \times 10^{6}$ ) with an inverse slope of $m=3$ or $m=5.5$. In Fig. 6(a), the equivalent stress per $10 \mathrm{~km} \sigma_{\text {eq/10 }}$ $\mathrm{km}$ is plotted on the vertical axis, and the frequency calculated by dividing the running distance corresponding to crack detection by 10 is plotted on the horizontal axis, together with the S-N curve. In the figure, the running distance corresponding to crack detection in the case of $\sigma_{e q / 10 \mathrm{~km}}$ is plotted on the horizontal axis shown above the diagram. 


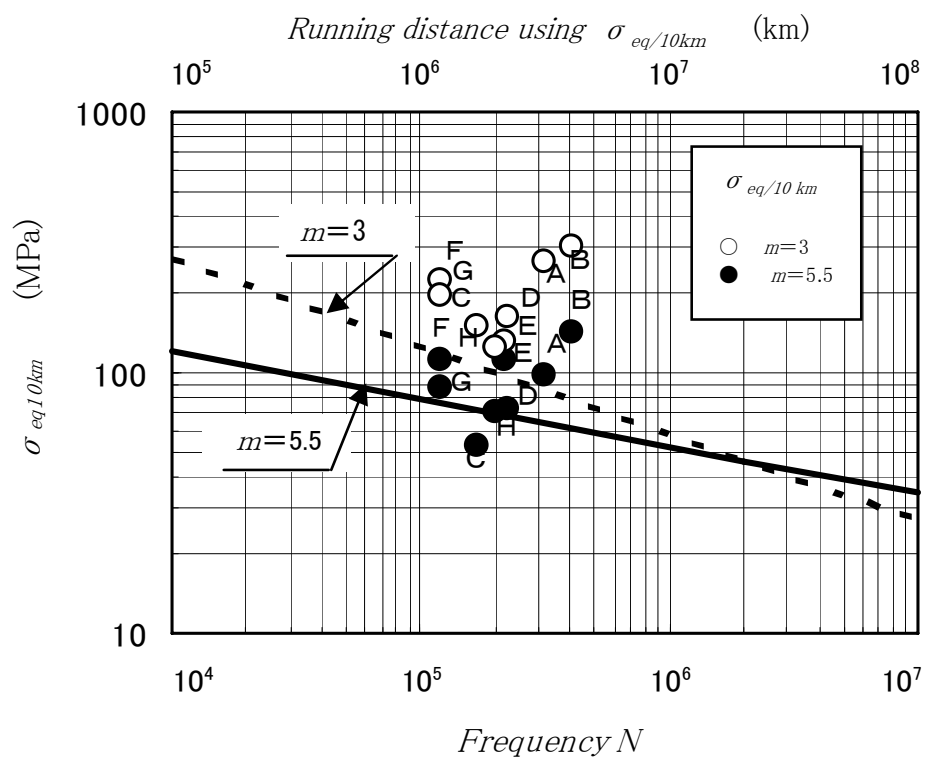

(a) Measurement positions $\mathrm{A}-\mathrm{H}$

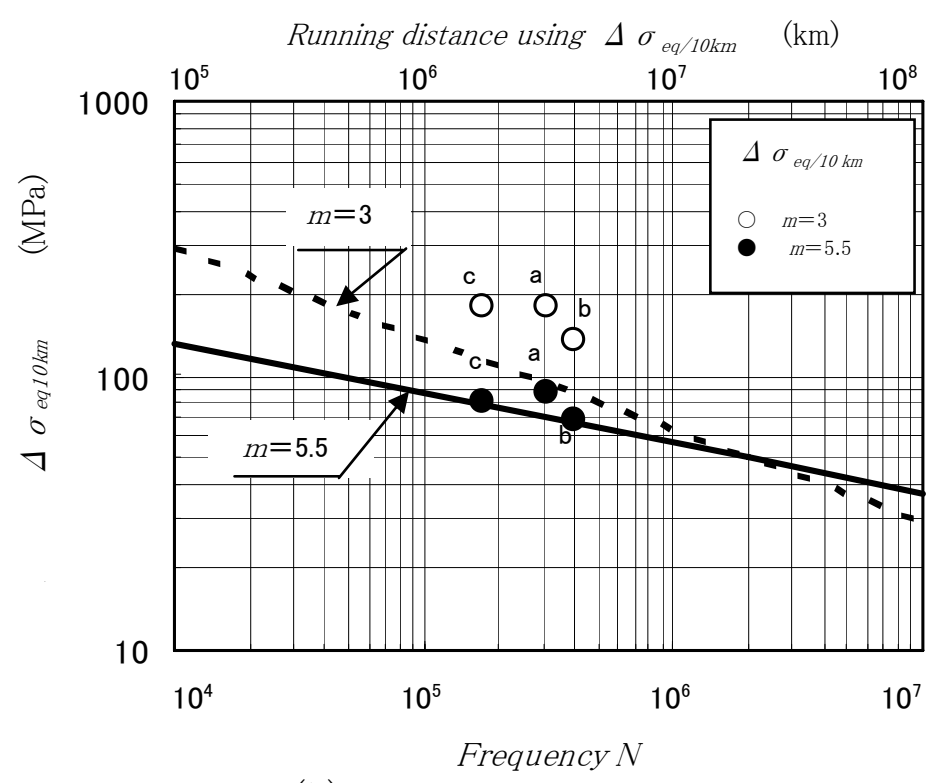

(b) Measurement positions a-c

Fig. 6 Relationship between the $\sigma_{e q / 10 \mathrm{~km}}$ value at which cracks appeared and the S-N curve

On the other hand, to estimate fatigue life at the toe of welds $\mathrm{A}, \mathrm{B}$ and $\mathrm{C}$ using the stress of measurement positions $\mathrm{a}, \mathrm{b}$ and $\mathrm{c}$ on the solid surface near the weld, the JSSC fatigue design curve with $m=3$ or the S-N diagram assumed from the 1974 JSSC fatigue design curve with $m=5.5$ were used. Examples of this fatigue life estimation are shown in Fig. 6(b) in the same way as in Fig. 6(a). The fatigue life at the toe of the weld is 
estimated using the nominal stress near the weld, where the class of the weld joint is $\mathrm{G}$ in the JSSC system and the stress range $\Delta \sigma$ at $2 \times 10^{6}$ is $50 \mathrm{MPa}$. Stress range $\Delta \sigma$ was plotted on the vertical axis in accordance with the JSSC fatigue design curve.

The equivalent stress per $10 \mathrm{~km} \sigma_{e q / 10 \mathrm{~km}}$ at the accumulated frequency corresponding to crack detection (i.e., the running distance corresponding to crack detection divided by 10) is distributed above the S-N curve (except in the case of measurement position $\mathrm{C}$ ) using $m=5.5$. This $\mathrm{S}-\mathrm{N}$ curve takes into account a safety value of about $20 \%$. As the probability of destruction is $0.1 \%$ according to JIS, and is the minimum limit of many data in JSSC, it is considered that the S-N curve should be prepared by simply moving the mean S-N curve downward in parallel by three times the standard deviation. The safety value was therefore assumed to be about $20 \%$, taking into account a fluctuation factor of 0.06 for the general S-N curve.

Considering the dispersion of running test conditions and the reliability of the running distance at crack detection, it is assumed that the dispersion will be about double on the frequency axis, or $15-25 \%$ on the stress axis. Accordingly, it does not necessarily hold that the equivalent stress per $10 \mathrm{~km} \sigma_{e q / 10 \mathrm{~km}}$ at crack detection exceeds the S-N curve, and as most $\sigma_{e q / 10 \mathrm{~km}}$ values are distributed above the S-N level, the estimation is considered appropriate.

As the dispersion of data at the measurement positions on the solid surface near the weld shown in Fig. 6(b) is less than the that at the measurement position on the toe weld shown in Fig. 6(a), estimation using the nominal stress of the solid surface near the weld seems to be superior.

\subsection{Fatigue life estimation using the degree of cumulative damage}

Examples of comparison between the damage degree distribution using $m=3$ and that using $m=5.5$ are shown in Fig. 7. Here, damage degree $n_{i} / N_{i}$ at stress $\sigma_{i}$ and stress range $\Delta \sigma_{i}$ are plotted on the vertical axis, and the ratio of $\sigma_{i} / \sigma_{\max }$ to $\Delta \sigma_{i} / \Delta \sigma_{\max }$ is plotted on the horizontal axis. The figure shows the damage degree distribution in the case of cumulative damage degree $\Sigma n_{i} / N_{i}=1$ at which cracking occurs. It seems that fatigue life is greatly influenced when using $m=3$ by regions where the stress amplitude is small and has many frequencies, while a similarly great influence results when using $m=5.5$ from regions where the stress amplitude is large (such as the maximum stress value) and has few frequencies. However, at measurement position D where large stress amplitude is predominant, little difference is seen in the influence on fatigue life between the case of using $m=3$ and that of using $m=5.5$.

Calculations of cumulative damage degree $\Sigma n_{i} / N_{i}$ according to the modified Miner's rule using the stress frequency distributions given in Fig. 3 are shown in Table 1. As most values of cumulative damage degree $\Sigma n_{i} / N_{i}$ (except a few examples in the case of using $m=5.5$ ) exceed 1, the estimation is considered appropriate, as discussed in Section 3.1. Here, the cumulative damage is generally closer to 1 for $m=5.5$ than for $m=3$.

In fatigue life estimation for railway rolling stock in which large stress amplitudes (such as the maximum stress $\sigma_{\max }$, i.e., $1.1-2.5$ times the strength at $2 \times 10^{6}$ ) should be taken into account and total frequency $\sum n_{i}$ is $10^{3}-10^{10}$, estimation using $m=5.5$ is considered to correspond more closely to actual conditions than that using $m=3$. This is because the small stress amplitude has a great influence on fatigue life when using $m=3$.

Since the dispersion of the cumulative degree of damage $\Sigma n_{i} / N_{i}$ at measurement positions a $-\mathrm{c}$ on the solid surface near the weld is less than the dispersion at measurement positions $\mathrm{A}-\mathrm{C}$ on the toe of the weld, estimation using the nominal stress of the solid surface near the weld can be thought to provide more reliable results. 


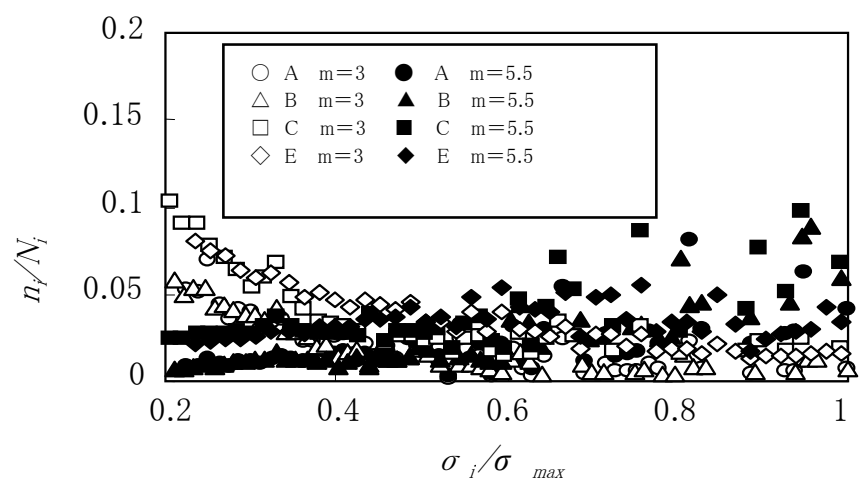

(a) Measurement positions A, B, C, E

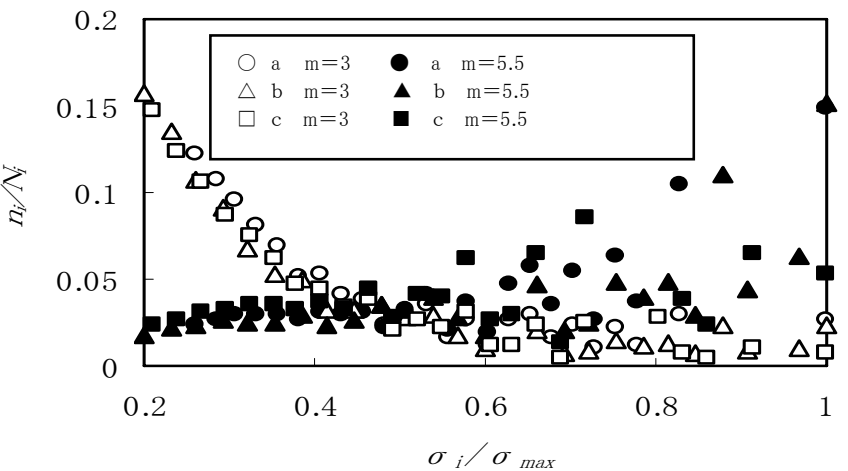

(b) Measurement positions a, b, c

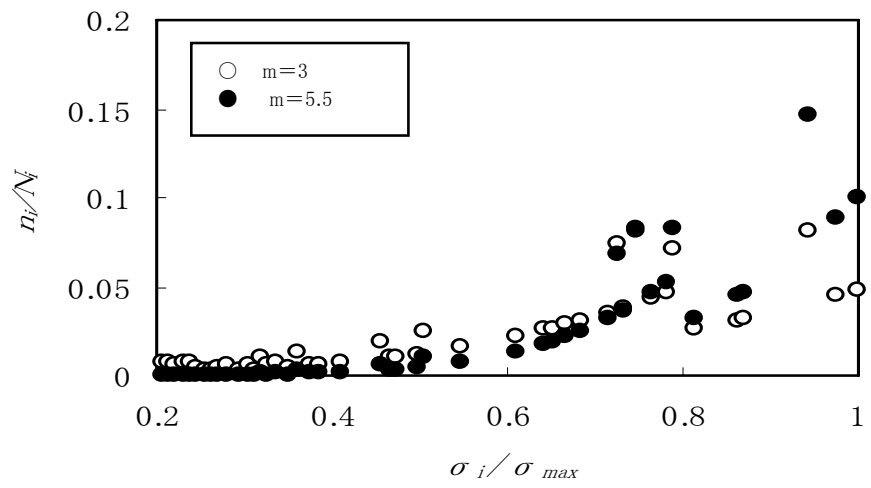

(c) Measurement positions D

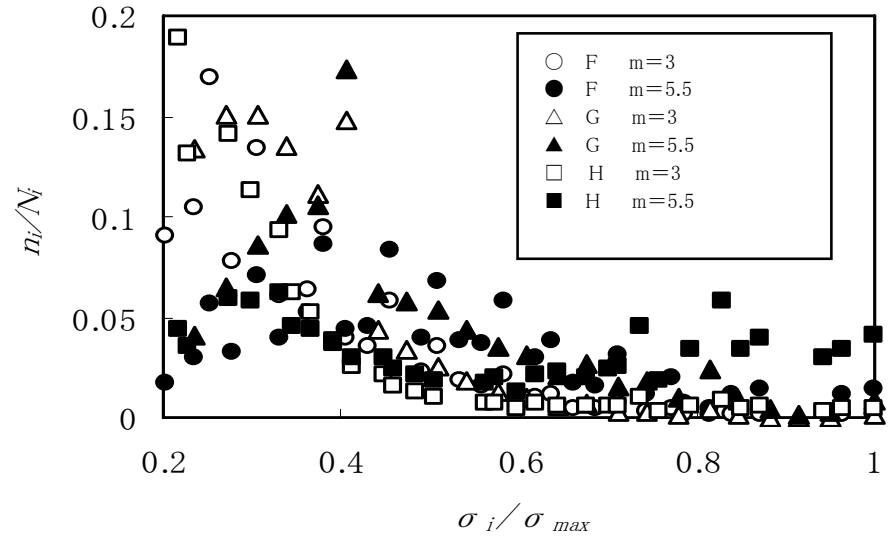

(d) Measurement positions F, G, H

Fig. 7 Results of cumulative damage degree distributions at $\Sigma n_{i} / N_{i}=1$ calculated according to the modified Miner's rule 
Table 1 Calculations of cumulative damage degree $\Sigma n_{i} / N_{i}$ according to the modified Miner's rule

\begin{tabular}{|c|r|r|r|}
\hline \multirow{2}{*}{ Measurement } & \multicolumn{2}{|c|}{$\begin{array}{l}\text { Cumulative damage degree } \\
\sum n_{i} / N_{i}\end{array}$} & $\begin{array}{c}\text { Crack } \\
\text { detection } \\
\times 10^{4}(\mathrm{~km})\end{array}$ \\
\cline { 2 - 3 } & $m=5.5$ & $m=3$ & 314 \\
$\mathrm{~A}$ & 9.24 & 13.1 & 314 \\
$\mathrm{a}$ & 3.11 & 5.23 & 407 \\
$\mathrm{~B}$ & 101.8 & 58.1 & 407 \\
$\mathrm{~b}$ & 1.19 & 3.91 & 171 \\
\hline $\mathrm{C}$ & 0.84 & 2.95 & 171 \\
$\mathrm{c}$ & 1.16 & 3.80 & 224 \\
$\mathrm{D}$ & 14.0 & 2.49 & 218 \\
$\mathrm{E}$ & 1.35 & 4.95 & 120 \\
$\mathrm{~F}$ & 7.06 & 6.67 & 120 \\
$\mathrm{G}$ & 0.76 & 4.62 & 200 \\
$\mathrm{H}$ & 0.76 & 1.62 & \\
\hline
\end{tabular}

\section{Conclusion}

This paper reports on the results of fatigue life estimation for welds on truck frames for rolling stock according to a modified Miner's rule. The three items used for this estimation were the S-N diagram assumed from the allowable stress values in JIS E 4207 or the JSSC fatigue design curve, the relationship between crack occurrence vs. running distance, and stress frequency distribution caused by service loads. The results can be summarized as follows:

(1) Most stress caused by service loads is distributed on the lines $\sigma_{i} / \sigma_{\max }=-\log \left(n_{i} / \Sigma\right.$ $\left.n_{i}\right) / \lambda$, where $\lambda=5-7$. Stress frequency distribution can therefore be approximately estimated from the maximum stress, e.g., the design stress assumed at the design stage.

(2) From examples of comparison between damage degree distribution using $m=3$ and that using $m=5.5$ with a cumulative damage degree of 1 , a strong influence on fatigue life was found using $m=3$ from regions where the stress amplitude is small and has many frequencies. Conversely, a strong influence on fatigue life was found using $m=5.5$ from regions where the stress amplitude is large (e.g., the maximum stress value) and has small frequencies.

(3) As most of the cumulative damage degree values calculated using stress frequency distributions at which cracks are detected exceeded 1, the estimation is considered appropriate. Here, the cumulative damage degree is generally closer to 1 when using $m=5.5$ than with $m=3$.

(4) In fatigue life estimation for railway rolling stock in which large stress amplitude (such as the maximum stress value) should be taken into account, estimation using $m=5.5$ is considered to correspond more closely to the actual circumstances than that using $m=3$. This is because the small stress amplitude strongly influences fatigue life in the case of using $m=3$. With calculation using $m=5.5$, the close correlation between the equivalent stress per $10 \mathrm{~km}$ and the maximum stress makes it convenient to relate $\sigma_{\text {eq } / 10 \mathrm{~km}}$ with estimation using the maximum stress of the JIS fatigue limit diagram.

(5) As the dispersion of the calculated cumulative damage degree at measurement positions on the solid surface near the weld is less than that at measurement positions on the toe of the weld, estimation using the nominal stress of the solid surface near the weld is considered to produce more reliable results. 
It is important to develop the engineering which can contribute to improvement of the environment. Accordingly, the progress of railway (environment-friendly in terms of discharge of $\mathrm{CO}_{2}$ ) engineering is an important element in the environmental engineering field. Results of this study could be helpful in keeping railway rolling stocks safe and reliable during their entire operational period.

\section{References}

(1) JIS E 4207-2004, Truck frames for railway rolling stock-General rules for design (2004).

(2) Tanaka, S., Proceedings of the435th Workshop of JSME, (1976-6), p. 98.

(3) Nagase, T., Strength and Maintenance of Weld Truck Frames (in Japanese), (1999), Kenyuusha.

(4) Japan Society of Steel Construction ed., Recommendation for Fatigue Design of Steel Structures (in Japanese), (1993), Gihoudo.

(5) H. Hobbacher, Recommendation for Fatigue Design of Welded Joints and Components, IIW Document XIII-1539-96/XV-845-96(1996).

(6) BS7608, Code of practice for fatigue design and assessment of steel structures (1993).

(7) JIS B 8821-2004, Calculation standards for steel structures of cranes (2004).

(8) Japan Road Association ed., Recommendation for Fatigue Design of Steel Road Bridge (in Japanese) (2002), Maruzen.

(9) JSSC Recommendation for Fatigue Design, JSSC Vol.10 No.101, (1974), Japan Society of Steel Construction.

(10) Miyaishi, G. et al., Endurance of the Bogie Frames of Shinkansen Vehicles, Quarterly Reports of RTRI, Vol. 32, No. 2 (1991), pp. 96-104.

(11) Oda, Y. et al., Characteristics of Stress Frequency in Welds of Vehicle Truck Frames by Service Load and Effect of Vehicle Running Conditions on Stress Frequency, Proceedings of the14th Transportation and Logistics Conference, No.05-52 (2005-12), pp. 351-354.

(12) Miyaishi, G. et al., Evaluation of Strength of Bogie Frames for High Speed Vehicles, RTRI Reports, Vol. 8, No. 7 (1994), pp. 19-24.

(13) Oda, Y. et al., Fatigue Life Estimation of Truck Frames Using the Case of Crack Occurrence and Stress Frequency in Service Load, Proceedings of J-Rail2002(2002-11), pp. 375-378. 